\title{
Effects of different concentrations of aqueous green tea extract against methotrexate-induced nephrotoxicity in rats
}

\author{
Farah Kais Abdul-Wahab*; Nada N. Al-Shawi*, Dawser K. Ismael* \\ *Department of Pharmacology and Toxicology, College of Pharmacy, University of \\ Baghdad, Iraq. \\ $\frac{\text { Received }}{\text { r.r.Y.I. Accepted }}$
}

ABSTRACT

Objective: The concentration-dependent nephroprotective effects of orally-administered aqueous green tea extract (AGTE) were studied.

Materials and Methods: Forty rats of both sexes (weighing $r \cdots-r_{0} \cdot g$ ) with various concentrations $\{\cdot . r 0 \%, 1 . r 0 \%$ and $r .0 \%$ of aqueous green tea extract (AGTE) $\}$ as their main source of drinking fluid $\checkmark$ days before and $\bullet$ days after administration of methotrexate (MTX). The parameters of oxidative stress, malondialdehyde (MDA) and reduced glutathione (GSH) were daily measured in kidney homogenate in addition to histopathological examinations after killing.

Results: Analysis of data revealed significant amelioration of oxidative stress in groups of animals treated with different concentrations of AGTE compared to MTX-treated group as evidenced by lowering MDA contents and elevation of GSH levels in kidney tissue homogenate but the levels still significantly different compared to controls. Furthermore, increasing concentrations of AGTE produce no concentration-dependent improvement of the damage induced by MTX in kidney tissue, as observed in kidney rats sections in concentrations $.7 r 0 \%$ and $r .0 \%$ AGTE, while improvement in renal morphological changes was observed in group of animals treated with 1. r $\% \%$ AGTE + MTX.

Conclusion: The concentration-dependent protective effects of AGTE against MTXinduce kidney damage were not evidenced, where higher concentration of AGTE ( $\uparrow .0 \%)$ used in this study resulted in deterioration in the renal functions and morphology, which may be due to its pro-oxidant effect; while renal protective effects was evidenced in a concentration of $1 . \mathrm{r} 0 \%$ AGTE, an effect that could be related to its antioxidant properties at this concentration.

Keywords: methotrexate, oxidative stress, nephrotoxicity, aqueous green tea extract.

الخهاف:تمة تصميم هذه الدرلسة لقفيم تركيز المستخلص المائي للثاي الأخضر الذي يمكن ان يكون له تأثير وقائي

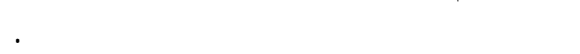

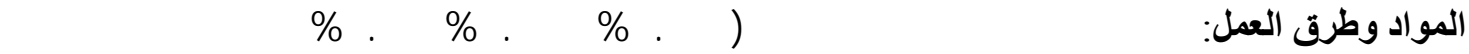

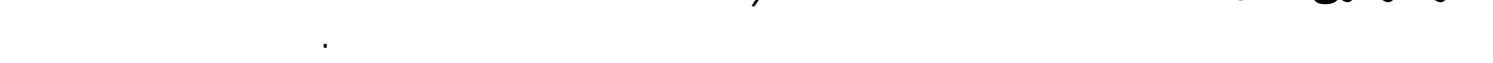

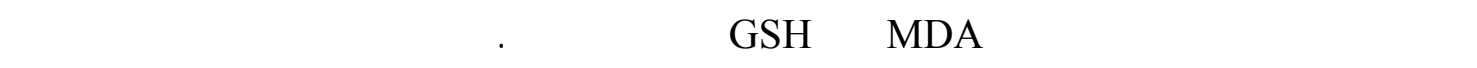

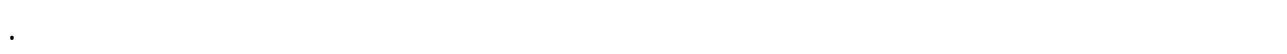

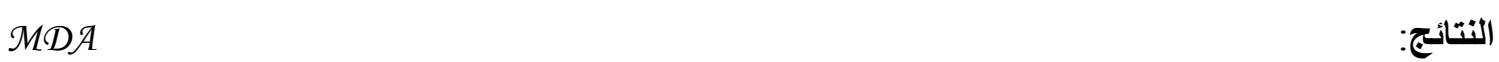

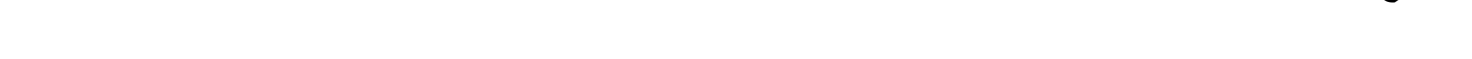

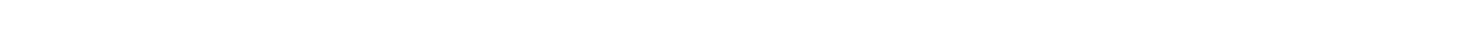
رفع نسبة GSH في النسج الكلوي لكن النسبة بقيت مختلفة بالمقارنة مع مجموعة السيطرة. 


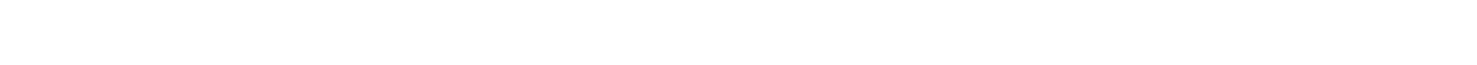

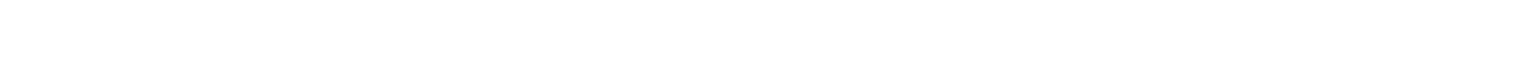

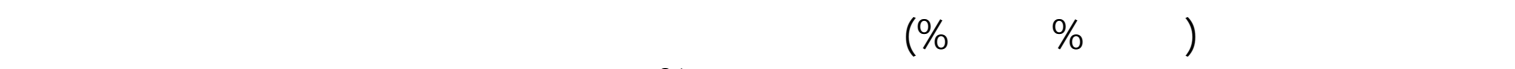

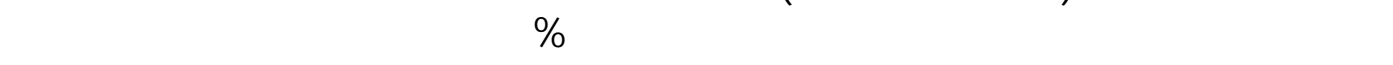

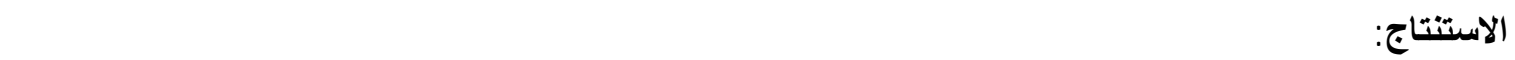

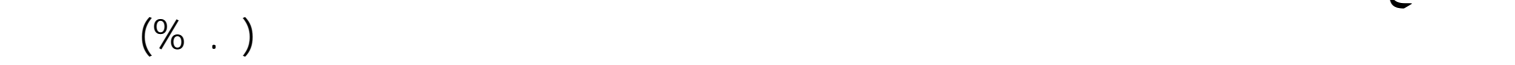

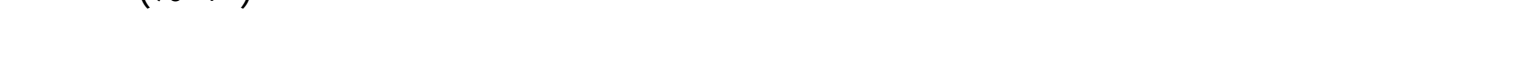

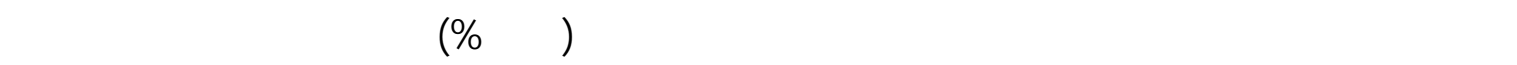
للأكسة في هذا التركيز.

M ethotrexate (MTX) an antimetabolite chemotherapeutic agent commonly prescribed for various cancers and autoimmune diseases'. Along with its effective therapeutic power, the drug has adverse effects on several organs, including the kidney ${ }^{r}$ especially when used at high dose ${ }^{r}$. The mechanism of MTX-induced renal toxicity have not yet been exactly established. Free radicals are supposed to play a role in methotrexate nephrotoxicity ${ }^{\varepsilon}$. More attentions have been paid to the protective effects natural antioxidants against drugs-induced toxicities especially whenever free radical generations are involved.

Green tea (Camellia sinensis) belongs to the family theacaceae, which is distributed through tropical and subtropical areas ${ }^{\gamma}$. The main constituents of green tea are the polyphenols, catechins, (-)-epigallocatechin- ${ }^{\top}$ - gallate (EGCG), (-)-epigallocatechin (EGC), (-)epicatechin-r-gallate (ECG) and (-)epicatechin (EC) ${ }^{\vee}$.

Epidemiologic and laboratory studies have reported that, green tea produces diverse beneficial health effects including antioxidant ${ }^{\wedge}$, hypocholesterolemic ${ }^{9}$, antihyperglycemic', chemo preventive" and anticarcinogenic'r effects. However, there is an increasing body of evidences to suggest the pro-oxidative effects of green tea in vitro" ${ }^{\prime r}$ and in vivo ${ }^{1:}$.
So far, there is no study regarding the protective effect of AGTE on methotrexate-induced renal impairment in vivo. Therefore, this study was designed to assess the concentration-dependent nephroprotective effects of orallyadministered AGTE against MTXinduced nephrotoxicity in rats.

\section{Methods}

\section{Preparation of Aqueous Green Tea Extract}

Aqueous green tea extract (AGTE) was freshly prepared daily by soaking for 1 . minutes .7ro g, $1 . r_{0} \mathrm{~g}$ and $r .0 \mathrm{~g}$, respectively of green tea leaves in $1 \cdots \mathrm{ml}$ of distilled water whose temperature was $9 .{ }^{\circ} \mathrm{C}$. Solutions then filtered to obtain the final $.7 r 0 \%, 1 . r 0 \%$ and $r .0 \%$, respectively of AGTE. The aqueous extracts were substituted water as the main source of drinking fluid in the 1. r $0 \%$ AGTE alone group and in the combination group animals ${ }^{10}$.

\section{Animals}

Forty white Albino rats of both sexes, weighing r...ro. $\mathrm{g}$ were used in this study; they were obtained from the animal house of the College of Pharmacy, University of Baghdad under conditions of controlled temperature. The animals were fed commercial pellets. Groups of animals that selected and served as control or those treated with MTX alone were fed tap water ad libitum; the re- 
mainder groups of animals that utilized in this study were fed with specific concentrations of AGTE as their main source of drinking fluid. Animal groups were divided as follows:

Group I- Seven rats were intraperitonealy (IP) injected normal saline for ir days. The animals were euthanized by anesthetic ether on the day $1 r$. The group served as control.

Group II- Seven rats were orally administered 1. $.0 \%$ AGTE as their sole source of drinking fluid for $1 r$ days. The animals were euthanized by anesthetic ether on the day $1 \mathrm{r}$.

Group III- Seven rats were injected IP $r \cdot \mathrm{mg} / \mathrm{kg}$ MTX for one day. Following this dose, saline was administered for ${ }^{\circ}$ consecutive days. The animals were euthanized by anesthetic ether on the day 7 . The group served as positive control of kidney damage ${ }^{17}$.

Group IV- Twenty rats were utilized to study the possible protective effects of various concentrations of AGTE ( . 7 r $0 \%, 1.40 \%$ and $r .0 \%$, respectively) \{given to rats as theirsole source of drinking fluid $\checkmark$ days prior to and $\bullet$ days after a single IP dose of MTX ( $r$. $\mathrm{mg} / \mathrm{kg}$ ). The animals were euthanized by anesthetic ether on the day $1 r$.

Kidney tissue homogenate was prepared by standard procedure ${ }^{\mathrm{IV}}$ and the contents of malondialdehyde (MDA) ${ }^{1 \wedge}$ and reduced glutathione $(\mathrm{GSH})^{19}$ were analyzed in kidney tissue homogenate. Small pieces of kidney tissues were prepared for histological examination according to standard procedure and evaluated by ordinary microscope after staining with hematoxyline and eosin ${ }^{r}$. Statistical analysis of data was performed utilizing Student's t-test and ANOVA. $90 \%$ confidence of data was considered for significance.

\section{Results}

Treatment of rats with single intraperitoneal (I.P.) injection of methotrexate $(\mathrm{MTX})(\boldsymbol{r} \cdot \mathrm{mg} / \mathrm{kg})$ produced a significant increase in the contents of lipid peroxidation end product, MDA $(0, \mathrm{r} \%)$ in renal tissue homogenate $(\mathrm{p}<\cdot . \cdot 0)$ compared to control group (Table ').

Oral administration of 1. r $0 \%$ AGTE alone to rats for $1 Y$ days, although provoked a reduction in MDA contents in kidney homogenate; but, still significantly higher contents of MDA were observed compared to control group $(\mathrm{P}<\bullet . \bullet)($ Table $)$.

Rats treated with an oral concentrations $(.7 r 0 \%, 1 . r 0 \%$ and $r .0 \%)$ of AGTE $\checkmark$ days prior to and $\bullet$ days after single IP injection of methotrexate $(r$. $\mathrm{mg} / \mathrm{kg}$ ) resulted in significant decline

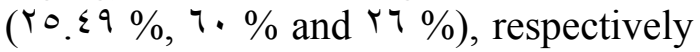
in renal MDA contents compared to MTX-treated group $(\mathrm{p}<\cdot .0)$; but still significantly higher ( $\sim \circ \vee . r \circ \%, 1 \leq 0.1 \vee \%$ and ror. $97 \%$ ), respectively compared to control $(\mathrm{p}<\bullet .0)$ as shown in Table 1.

Concerning the lowering of renal MDA contents, a significant difference was observed in groups of animals treated with 1. $.0 \%$ AGTE with respect to both $.7 r 0 \%$ and $r .0 \%$ AGTE concentrations $(\mathrm{p}<\cdot . \bullet)$ (Figure 1$)$.

With regard to the renal tissue GSH levels, the results showed that, there was a highly significant decrease in the levels of GSH $(\vee \wedge . \wedge \vee \%)$ in the renal tissue homogenate in MTX-treated rats compared to control group $(\mathrm{p}<\bullet .0)$ (Table ').

Oral administration of 1. r $0 \%$ AGTE alone to rats for ir days, produced a non-significant difference $(\mathrm{p}>\cdot . \cdot 0)$ in the level of GSH in renal tissue homogenate compared to control group as shown in Table '.

Rats treated with oral concentrations $(\cdot . r 0 \%, 1 . r 0 \%$, and $r .0 \%)$ of AGTE $\vee$ 
days before and $\bullet$ days after a single IP injection of methotrexate ( $r \cdot \mathrm{mg} / \mathrm{kg}$ ) produced a significant increase in the renal tissue homogenate GSH levels ( 1 \% . r \% \%, r $10.1 \% \%$ and $т \vee . \varepsilon r \%$ ), respectively compared to MTX-treated group $(\mathrm{p}<\cdot . \cdot 0)$ and a non-significant difference $\left(\mathrm{P}>\cdot . \bullet^{0}\right)$ was observed in the level of GSH in renal tissue homogenate of rats treated with 1. $.0 \%$ AGTE $\vee$ days prior to and ${ }^{\circ}$ days after MTX compared to controls, but there were significant differences $(\mathrm{P}<\cdot . \bullet)$ concerning renal GSH levels in animals treated with both . 7 T $0 \%$ and $r .0 \%$ AGTE compared to control group as shown in (Table ').

In comparison between the different concentrations of orally administered AGTE on GSH levels of the renal tissue homogenate, there was a significant increase $(\mathrm{p}<\cdot .0)$ in the levels of glutathione in animals treated with $1 . r 0 \%$ AGTE with respect to both $\cdot T r 0 \%$ and $r .0 \%$ concentrations as shown in (Figure r).

Renal tissue histology of rats treated with MTX showed moderate degenerative changes, shrinkage and disruption of glomeruli, mild feathery degeneration and increased cytoplasmic granularity (eosiniphilia) in the proximal convoluted tubules (PCTs) with tubular hypertrophy of the distal convoluted tubules (DCTs) compared to normal kidney (Figures $r$ and $\varepsilon$ ).

Sections of rats' kidney treated with 1. r $0 \%$ AGTE alone for Ir days showed mild congestion of glomerular capillaries, intact proximal and distal convoluted tubules. (Figure ${ }^{\circ}$ ).

Histological examination of the kidneys belong to rats treated with $\cdot 7 r 0 \%$ AGTE $\vee$ days prior to and $\bullet$ days after a single i.p dose of MTX, showed moderate disruption of glomeruli, narrowing of PCT lumina and sometimes complete oblitration of their lumen with obvious plumpy cell lining of the DCT (Figure 7).

Sections of rats' kidney treated with 1. ${ }^{\circ} \%$ AGTE $\vee$ days prior to and $\bullet$ days after a single i.p dose of methotrexate to rats, showing improvement in renal degeneration compared to methotrexate treated group and the improvement characterized by mild disruption of glomeruli, very mild focal degenerative changes of PCT with negligible changes in DCT. (Figure $\vee$ ). Sections of rat's kidney treated with $Y .0 \%$ AGTE $V$ days prior to and ${ }^{\circ}$ days after a single i.p dose of methotrexate, showed glomerular mesangeal edema; there was an oblitration of lumina with degeneration in the PCTs, with hypertrophy of the DCTs (Figure ᄉ). 
Table '. The Effects of treatment with different concentrations of aqueous green tea extract (AGTE) and '. $\mathrm{Y} \% \%$ AGTE alone on the levels of MDA and GSH in rats' renal homogenate compared to MTX-treated and control groups.

\begin{tabular}{|c|c|c|}
\hline Groups & MDA (nmol/g tissue) & $\mathrm{GSH}(\mu \mathrm{mol} / \mathrm{g}$ tissue $)$ \\
\hline $\begin{array}{l}\text { Control } \\
(n=v)\end{array}$ & $\vee \backslash \wedge \pm 1 \cdot Y .7 T$ & $1 \cdot . r+1.97$ \\
\hline $\begin{array}{l}\operatorname{MTX}(r \cdot \mathrm{mg} / \mathrm{kg}) \\
(\mathrm{n}=\mathrm{V})\end{array}$ & $\varepsilon \varepsilon \cdot v .1{ }^{\prime} \pm \varepsilon 07.1 \Lambda^{*}$ & $r .11 \pm \cdot .10^{*}$ \\
\hline $\begin{array}{l}\text { 1. Y०\% AGTE } \\
(n=7)\end{array}$ & $9 \leq 7.01 \pm r 0.19^{*}$ & $9.9 \pm \cdot .7 r$ \\
\hline $\begin{array}{l}\text { MTX }+ \text { AGTE } \cdot .7 r \circ \% \\
(n=\vee)\end{array}$ & 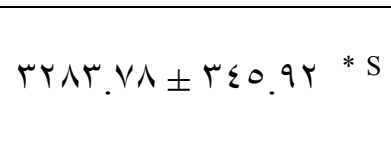 & $0.1 r \pm \cdot .00 * S$ \\
\hline $\begin{array}{l}\text { MTX + AGTE '. Y०\% } \\
(n=\vee)\end{array}$ & $|V T \cdot r 0 \pm r \leq V . r| * S$ & $9.0 \pm 1.1^{s}$ \\
\hline $\begin{array}{l}\text { MTX + AGTE Y.०\% } \\
(n=7)\end{array}$ & rr०q.0 \pm rrq. $\Sigma \Lambda * S$ & $r .70 \pm \cdot .7 \varepsilon$ * S \\
\hline
\end{tabular}

Data are presented as mean \pm SEM., $\mathrm{n}=$ number of animals, ${ }^{*} \mathrm{P}<\cdot .{ }^{\circ}$ with respect to control group, $\mathrm{S}=$ significant difference with respect to MTX-treated group. 
Irq J Pharm Vol. '1, No. ',

$r \cdot 11$

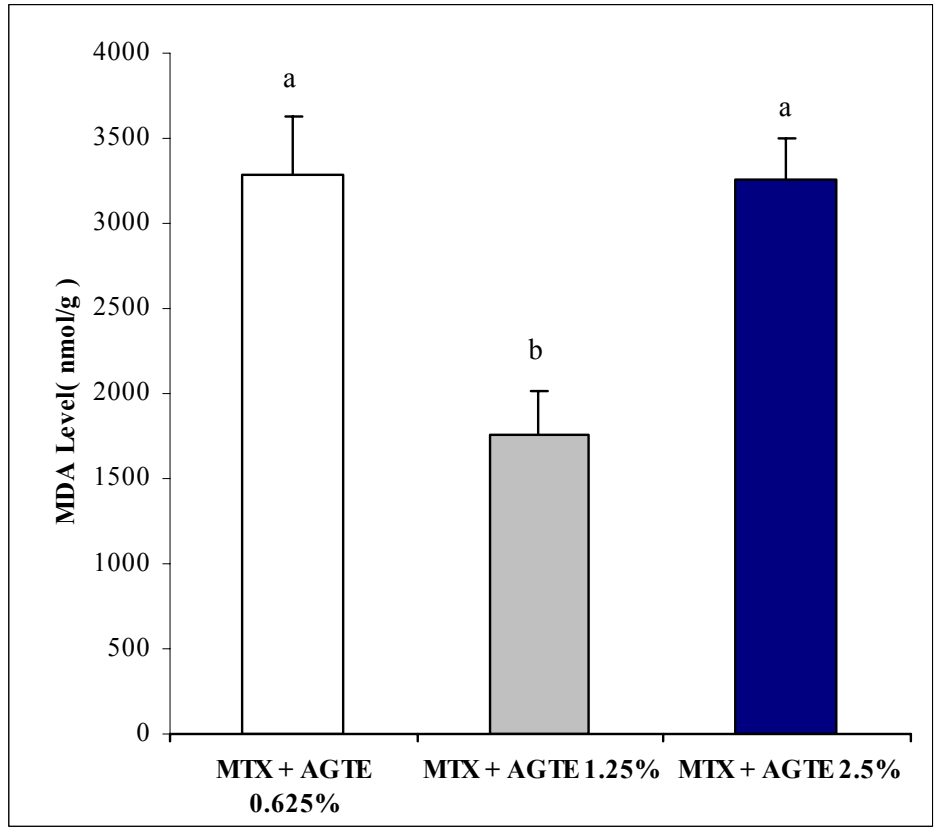

Figure 1. Bar chart comparing the effects of different concentrations of AGTE administered $V$ days prior to and ${ }^{\circ}$ days after methotrexate treatment on renal MDA contents. Values with non-identical superscripts ( $\mathrm{a}$ and $\mathrm{b})$ are considered significantly different $(\mathrm{p}<$ $\because \cdot 0)$

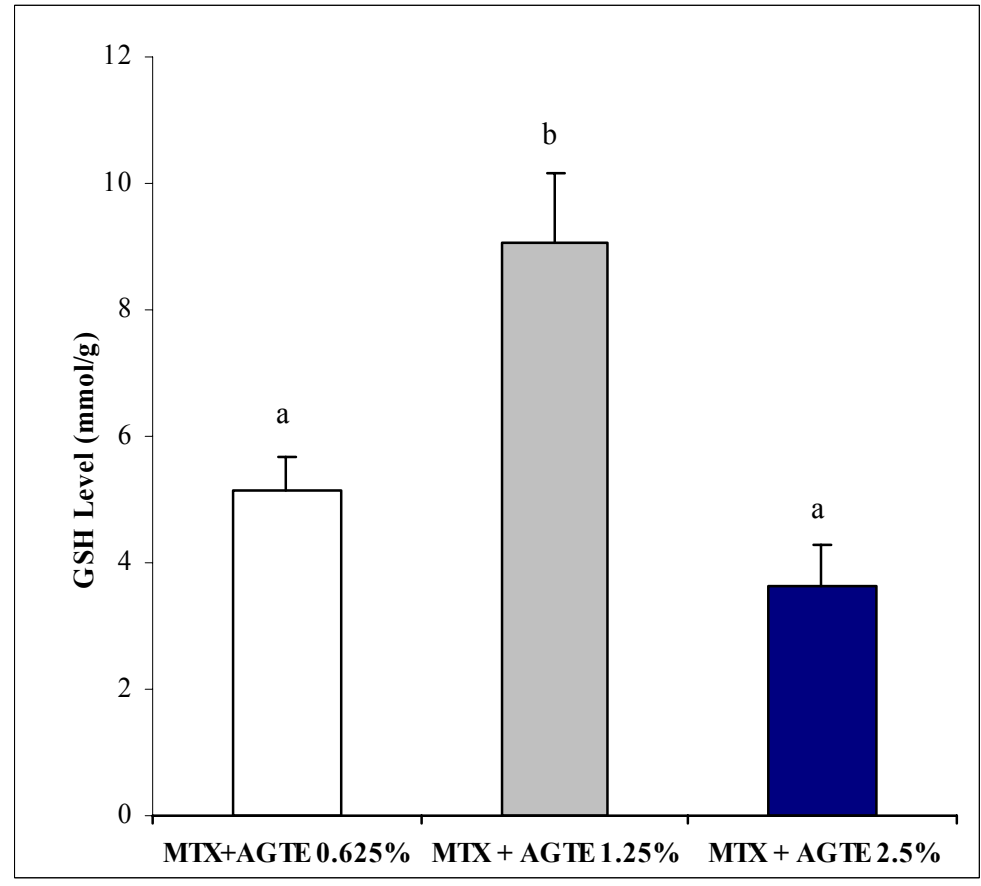

Figure $r$. Bar chart comparing the effects of different concentrations of AGTE administered $\vee$ days prior to and ${ }^{\circ}$ days after methotrexate treatment on renal GSH levels. Values with non-identical superscripts $(a$ and $b)$ are considered significantly different $(p<\cdot .0)$ 
Irq J Pharm Vol. '1, No. ',

$r, 11$
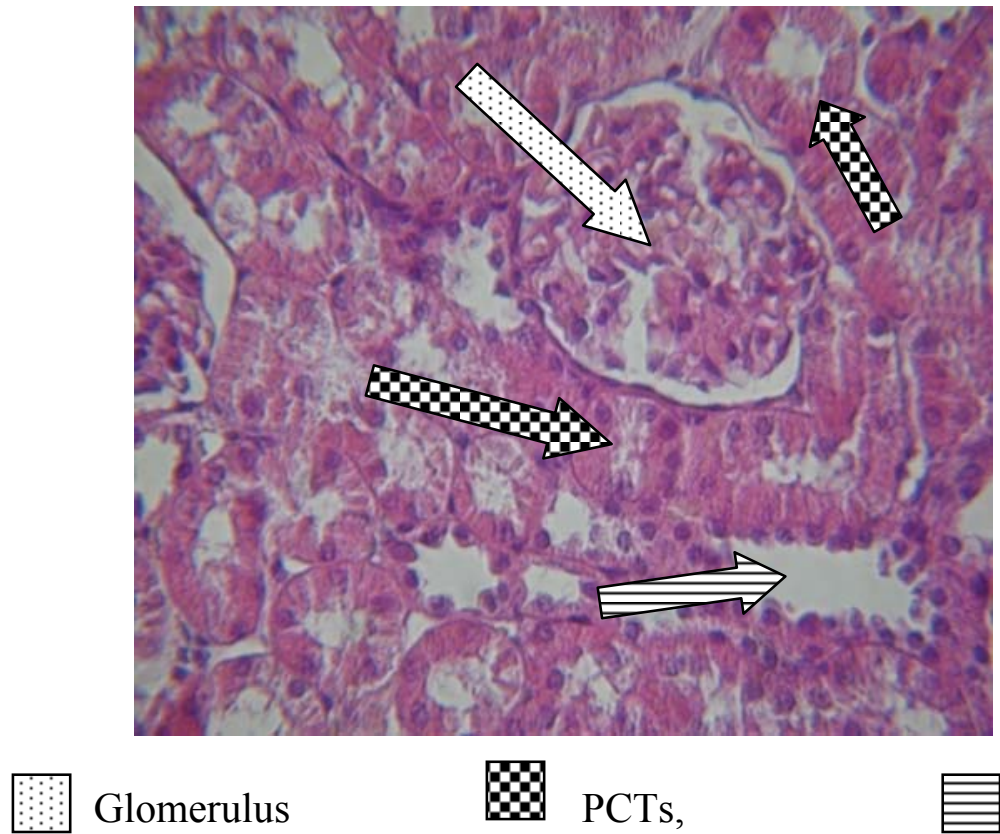

PCTs,

DCTs

Figure $r$. Section showing normal rat's kidney. PCTs, proximal convoluted tubules, DCTs, distal convoluted tubules. Magnification: $(\varepsilon \cdots X)$; staining:Haematoxylline and Eosin.
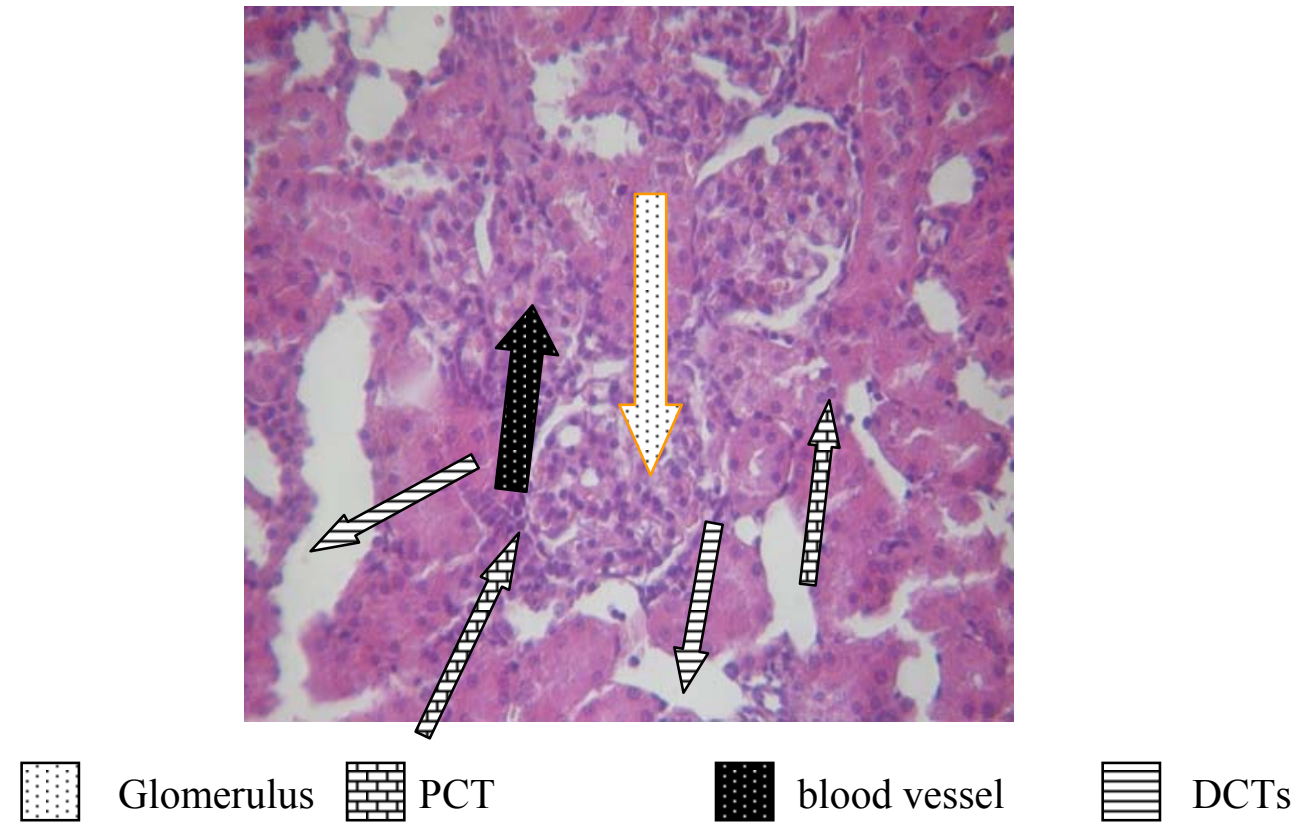

Figure $\leqslant$. Section showing morphological alteration of rat's kidney treated with methotrexate, 
Irq J Pharm Vol. ' ', No. ',

$r .11$
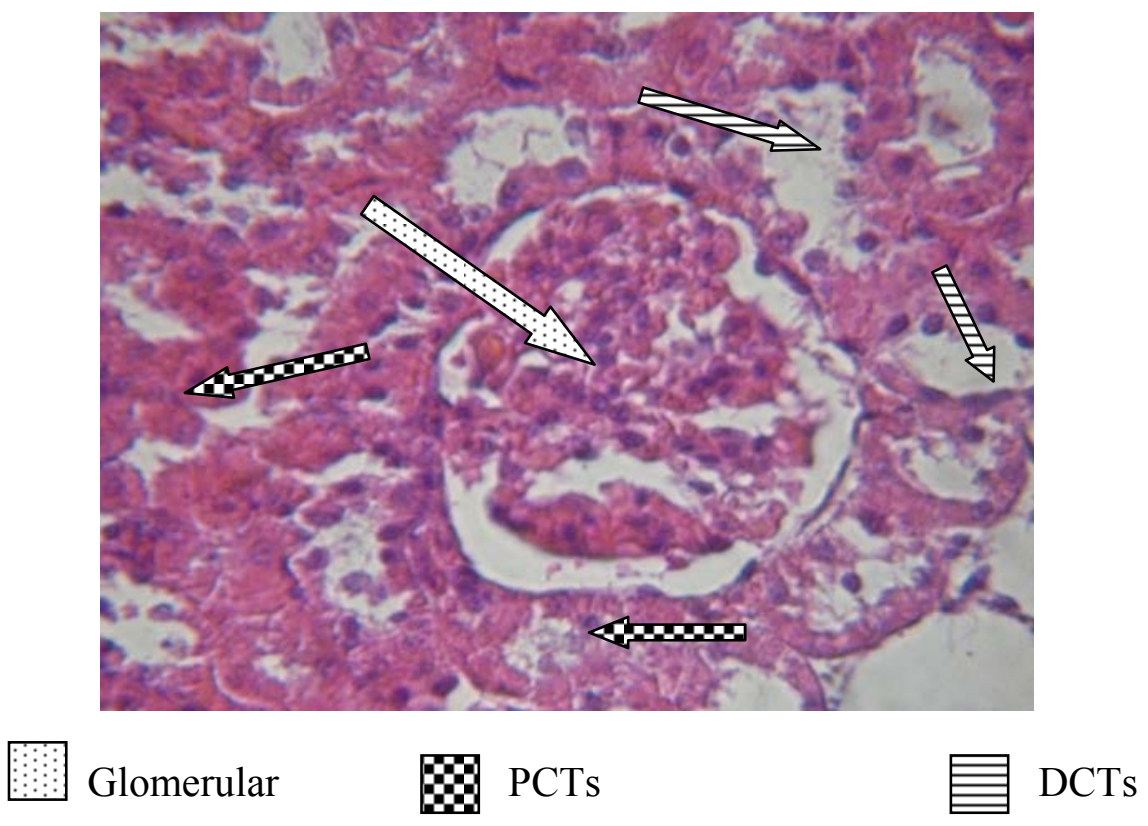

Figure ${ }^{\circ}$. Section of rat's kidney treated with 1. r $0 \%$ aqueous green tea (AGTE) alone for $i r$ days.
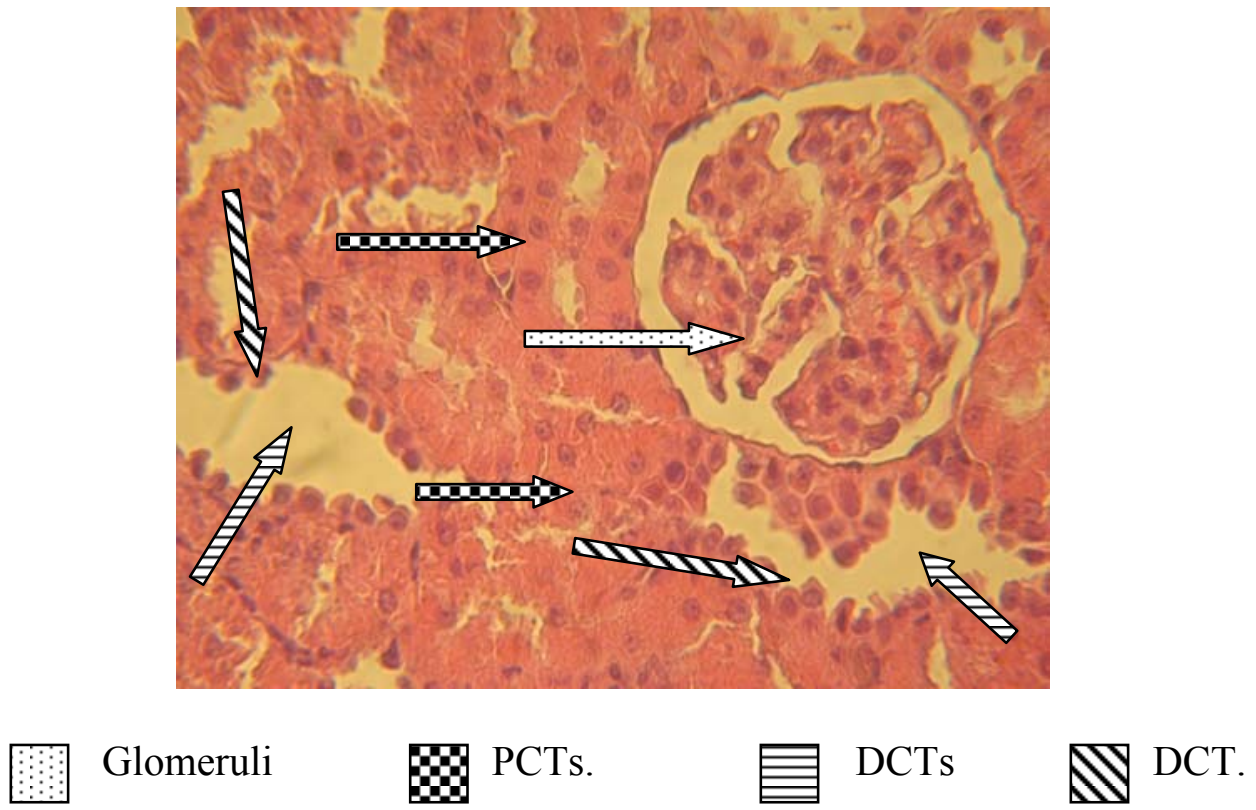

Figure 7 . Section of rat's kidney showing the effect of treatment with •.7ro\% AGTE $V$ days prior to and $\bullet$ days after methotrexate. 
Irq J Pharm Vol. ' ', No. ',

$r, 11$

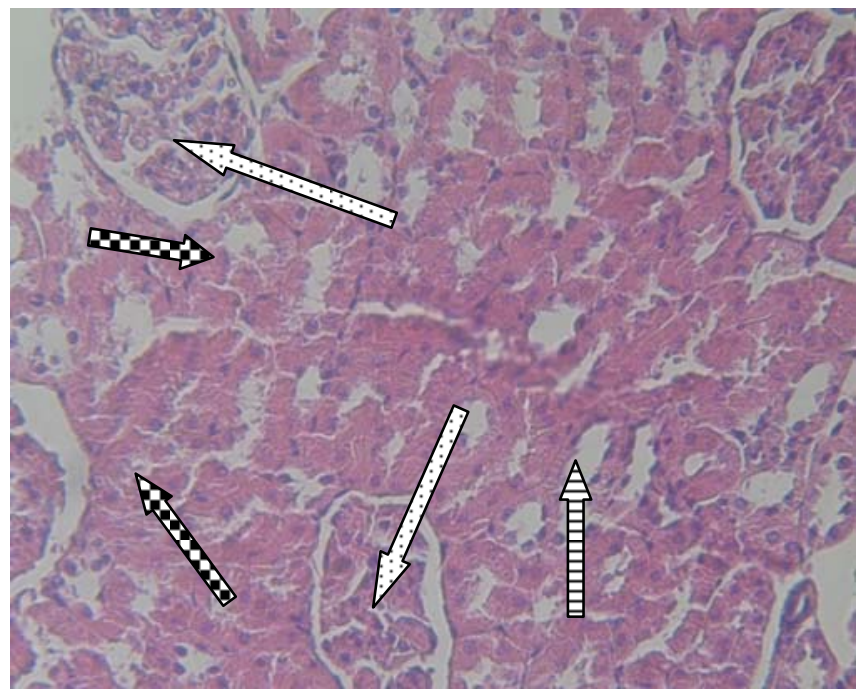

Glomerulus

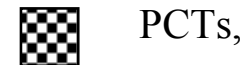

DCTs

Figure $\vee$. Section of rat's kidney showing the effect of treatment with '. $Y 0 \%$ AGTE $\vee$ days prior to and $\bullet$ days after methotrexate.
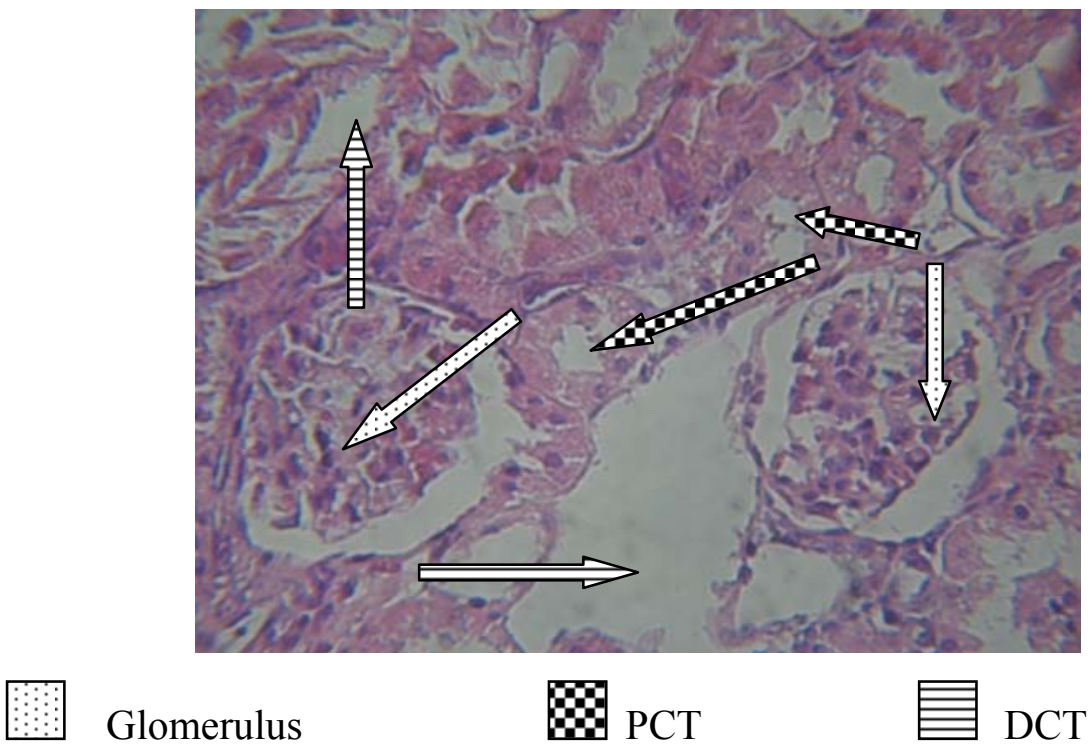

Figure ${ }^{\wedge}$. Section of rat's kidney showing the effect of treatment with $r .0 \%$ AGTE $\checkmark$ days prior to and ${ }^{\circ}$ days after methotrexate. 


\section{Discussion}

In this study, the renal damage elicited by MTX appears to be secondary to the elevation of the MDA contents and a significant reduction in GSH level in renal tissue homogenate were observed after a single IP injection of $r \cdot \mathrm{mg} / \mathrm{kg}$ MTX to rats (Table '). Our results are consistent with those observed by other authors, suggesting that, lipid peroxidation that is mediated by oxygen free radicals, may be a contributing factor to the development of MTX-mediated kidney Damage ${ }^{r}$.

Possible mechanism of ROS generation by MTX is that nitric oxide (NO) level in kidney tissue was increased by the MTX administration, and appears to be involved in superoxide-mediated tissue injury ${ }^{r}$.

Furthermore, different chemical agents with free radical scavenging and antioxidants properties namely, $\beta$ glucan, L-Carnitine, Caffeic acid phenethyl ester, $\mathrm{N}$-acetylcysteine and taurine ${ }^{r-r_{0}}$ have been shown to protect against nephrotoxicity induced by MTX in animal models and suggest that oxidative stress plays an important role in the MTX-induced nephrotoxicity.

The kidneys are highly dependent on an adequate supply of GSH, (an important molecule that maintains normal cellular antioxidant defenses) ${ }^{r}$; due to high rates of aerobic metabolism, particularly in the proximal convoluted tubules (PCTs) and high concentrations of oxidants and reactive electrophiles where the kidneys are potentially exposed to.

Renal tissue levels of GSH are maintained by both intracellular synthesis and transport from outside the cell ${ }^{\Upsilon Y}$. The significant reduction in GSH le- vels promoted by MTX represents an alteration in the cellular redox state, suggesting that the cells could be more sensitive to reactive oxygen metabolites $^{r \wedge}$, and leads to a reduction of effectiveness of the antioxidant enzyme defense systems, superoxide dismutase (SOD), glutathione peroxidase (GSH$\mathrm{Px})$ and catalase $(\mathrm{CAT})^{r q, r \cdot}$.

With the regard to the histological changes seen in kidneys of animals treated with MTX, the present work showed that, there were disruptions of glomeruli, mild degeneration of PCT, increased cytoplasmic granularity, with tubular hypertrophy of the distal convoluted tubules (DCTs) (Figure $\varepsilon$ ), which are consistent with the results of other investigators, where oxygen free radicals are believed to be an important cause of damage to renal tissues induced by MTX $^{\text {Yr }}$ and subsequent detrimental effects on DNA, proteins, lipids and other cellular structures ${ }^{r}$.

Rats orally treated with various concentrations of AGTE $\vee$ days prior to and $\bullet$ days after MTX, resulted in a significant decrease in MDA contents in renal tissue homogenate compared to MTX-treated group but still significantly higher compared to control group (Table ').

It was demonstrated that, tea catechins, including EGCG possesses both antioxidant and pro-oxidant activities because of its unique ability to autooxidation and acts as a hydrogen donor ${ }^{r \prime}$. Thus, conflicting data were obtained concerning these respects.

Balaraman et al in $r . .0$ demonstrated that, treatment with green tea extract offered a significant protection from the cisplatin-induced oxidative damage to kidneys ${ }^{r r}$. 
In the contrary, Bing et al in $r . . v$ demonstrated that, EGCG was shown to produce a concentration-dependent antipower on iron ions. The predomination of reducing power on iron ions over ROS scavenging activity of EGCG at higher concentrations might results in the prooxidant effect of EGCG on DNA ${ }^{r r}$.

It has been shown that, the pro-oxidant effect of EGCG was similar to that obtained by ascorbic acid, which acts as a pro-oxidant in the presence of free transition metal ions by accelerating the Fenton reaction and lipid peroxidation ${ }^{r \varepsilon}$. Moreover, some phenolic compounds at higher concentrations were reported to have the ability of reducing iron ions and generating the cytotoxic hydroxyl radical from the Fenton reaction in culture media ${ }^{{ }^{\circ}}$.

From the present data, we can conclude that, orally administered 1. . $0 \%$ AGTE $V$ days prior to and $\bullet$ days after MTX produced protective effect against nephrotoxicity induced by the drug in rats which may be due to antioxidant effect at this concentration. Furthermore, the concentration-dependent pattern of nephronprotection is not evident, where higher concentration of AGTE showed marked pro-oxidant properties.

\section{References}

1. Widemann BC, Balis FM, KempfBielack B, et al. High-dose methotrexate-induced nephrotoxicity in patients with osteosarcoma: incidence, treatment, and outcome. Cancer r...s;1..:rrrr_rr.

r- Abelson HT, Fosburg MT, Beardsley GP, et al. Methotrexate-induced renal impairment: clinical studies and rescue from systemic toxicity with high-dose leucovorin and thymidin. J Clin Ocol

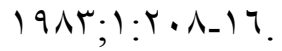

oxidant or prooxidant effect on DNA depending on the balance of the two activities, ROS scavenging and reducing

r - Hemple L, Misselwitz J, fleck C, et al. Influence of high dose methotrexate therapy (HD-methotrexate) on glomerular and tubular kidney function. Med PediatOncol $r \ldots r ; \varepsilon \cdot: r \leqslant \Lambda_{-}$ oร.

¿- Ali C, Ergul BK, Ertan B, Bulent $\mathrm{K}$. The effects of $\mathrm{N}$-acetylcysteine on methotrexate-induced oxidative renal damage in rats. Nephrology Dialysis. Transplantation $r . . \vee ; r r: r \wedge \leq-r \wedge 0$.

- Ojo OO, Ladeji O. Hepatoprotective and antioxidant effects of Camellia sinensis (black tea) in rats. Afr $\mathrm{j}$ Bio-

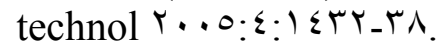

7. Bun SS, Bun, H, Gue don D, et al. Effect of green tea extracts on liver functions in Wistar rats. Food and Chemical Toxicology r.. T; s: $11 \cdot \Lambda_{-} 111 \%$.

V- Nakagawa T, Yokozawa T. Direct scavenging of nitric oxide and superoxide by green tea. Food Chem Toxicol $r \cdot . r ; \varepsilon \cdot: \mid$ ) $\vee \leqslant 0 \_0$.

^. Rice-Evans CA, Miller N J, Paganga G. Structure-antioxidant activity relationships of flavonoids and phenolic acids. Free Radic Biol Med 1997; $r \cdot: 9 r r-907$.

१. Lin YL, Cheng CY, Lin YP, et al. Hypolipidemic effect of green tea leaves through induction of antioxidant and phase II enzymes including superoxide dismutase, catalase, and glutathione $\mathrm{S}$-transferase in rats. $\mathrm{J}$ Agric Food Chem 1991; $\left\{7: 1 \wedge 9 \Gamma_{-}\right.$ 99 .

1.-Sabu M C, Smitha K, Kuttan R. Anti-diabetic activity of green Tea polyphenols and their role in reducing oxidative stress in experimental diabetes. J Ethnopharmacol $r . . r$; Nr:1.9-17. 
1)-Fujiki H, Suganuma M, Matsuyama $\mathrm{S}$, et al. Cancer prevention with green tea polyphenols for the general population, and for patients following cancer treatment. Curr Cancer Ther Rev Y...0;1:1.9-1 $\leqslant$.

I r-Hayakawa S, Kimura T, Saeki K, et al. Apoptosis-inducing activity of high molecular weight fractions of tea extracts. Biosci Biotechnol Biochem Y.. 1; 70:509_7r.

$1 \mathrm{r}$-Weisburg JH, Weissman DB, Sedaghat $T$, et al. In vitro cytotoxicity of epigallocatechin gallate and tea extracts to cancerous and normal cells from the human oral cavity. Basic Clin Pharmacol Toxicol Y.. $\leqslant ; 90: 191-$ r...

1 \&-Joshua DL, Shengmin S, Yang CS. Possible Controversy over Dietary Polyphenols: Benefits vs Risks.Chem. Res Toxicol r..V;r.:ONr_o.

1॰-Maity S, Vadasiromoni J, Ganguly D. Role of glutathione in the antiulcer effect of hot water extract of black tea. Jpn J Pharmacol

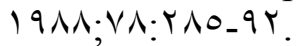

17 -Mustafa Ç, Göksel ŞA, Özer Ş, et al. Taurine protects against methotrexate-induced toxicity and inhibits leukocyte death. Toxicol Appl Pharmacol r...0; r. 9:rq_o.

IV-Bhattacharyya D, Pandit S, Mukherjee $\mathrm{R}$, et al. Hepatoprotective effect of Himoliv $^{\circledR}$, a poly herbal formation in rats. Ind $\mathbf{J}$ Physiol Pharmaol $r \cdot . r ; \leqslant \vee(r): \leqslant r 0_{-} \varepsilon \varepsilon \cdot$

1^-Buege JA, Aust SD. Microsomal lipid peroxidation. Methods Enzy |9VA;Or:r.r.r!.

19-Ellman, GL. Tissue sulfhydryl groups. Arch. Biochem. Biophys 1909;Ar(1):V・-VV. r.- Junqueira, LC, Carneiro J, Kelley R. Basic Histology. $\wedge^{\text {th }}$ Ed, Lange Medical Book, 1990; pp. I-r, r.G-r I $\leq G$.

Y -Ener GS, sio glu-Demiralp E, Etiner $\mathrm{MC}$, et al. L-Carnitine ameliorates methotrexate-induced oxidative organ injury and inhibits leukocyte death. Cell Biol Toxicol $r \ldots r$; $Y$ r: $\leqslant \vee-7$.

r r-Uz E, Faruk KH, Ramazan Y, et al. The activities of purine-catabolizing enzymes and the level of nitric oxide in rat kidneys subjected to methotrexate: Protective effect of caffeic acid phenethylester. Mol Cellular Bioch Y. . O Y YVV: I TO_IV.

$r^{r}$-Göksel Ş, Ekşioğlu-Demiralp, E, Mustafa Ç, Ercan F, et al. $\beta$-glucan ameliorates methotrexate-induced oxidative organ injury via its antioxidant andimmunomodulatory effects. Eur $J$ Pharmacol $Y . . \cdot$; $0 \leq Y: \mid V \cdot-I V \Lambda$.

$r \leqslant$-Faruk Ok, Ramazan YH, Ozgunerc F, et al. Methotrexate-induced renal oxidative stress in rats: the role of a novel antioxidant caffeic acid phenethylester.Toxicology and Industrial Health $r \cdots r ; r r: r \leq 1-r \leq r$.

ro-Ali C, Ergul BK, Ertan B, Bulent $\mathrm{K}$. The effects of $\mathrm{N}$ - acetylcysteine on methotrexate-induced oxidative renal damage in rats. Nephrology Dialysis Transplantation

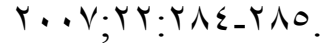

$r$ צ-Przybtkowski E, Averill-Bates DA. Correlation between glutathione and stimulation of the pentose phosphate cycle in situ in Chinese hamster ovary cells exposed to hydrogen peroxide. Arch Biochem Biophys. 1997 ; rYO: 91-A.

$r v$-Lawrence HL. Role of glutathione transport processes in kidney function. Toxicol Applied Pharmacology $r \cdot 0 ; r \cdot \varepsilon: r r q-r \leqslant r$. 
$r \wedge$ - Goldman D. Analysis of the cytotoxic determinants for methotrexate (NSC-V ₹•): a role for free intracellular drug. Cancer Chemother Rep 19v0;7:01-71.

rq- Babiak RM, Campello AP, Carnieri, et al. Methotrexate: pentose cycle and oxidative stress. Cell Biochem Funct 199^;1 7: r人r_qr.

r.-Lee SM, Koh HJ, Park DC, et al. Cytosolic NADP $(+)$ - dependent isocitrate dehydrogenase status modulates oxidative damage to cells. Free Radical Biology and Medicine. r... r; r r: $1110_{-} 97$.

r-Mandel S, Weinreb O, Amit T,Youdim. Cell Signaling pathways in the neuroprotective actions of the green tea polyphenol(-)- epigallocatechin-r-gallate: implications for neurodegenerative diseases. J Neurochem Y.. ₹;^ᄉ: 1000_1079.

rr-Balaraman LP. Effect of green tea extract on cisplatin induced oxidative damage on kidney and testes of rats. Ars Pharm Y...0; $\left\{7: 0_{-}\right) 1$.

$r$ r-Ross JA. Dietary flavonoids and the MLL gene: a pathway to infant leukemia? Proc Natl Acad Sci USA r...;qV: $: \leqslant \leqslant 11-r$.

$r \varepsilon-W i s e m a n$ SA, Balentine, DA, Frei B. Antioxidants in tea. Crit Rev Food Sci Nutr $199 \vee ; r \vee: \vee \cdot 0_{-} \vee / \wedge$.

ro-Kanwaljit C. Nephrotoxicity and its prevention by catechin in ferric nitrilotriacetate promoted oxidative stress in rats. Human Experim Toxicol $\left.r_{0} \cdot \varepsilon ; r r: 1 r V_{-}\right) \leqslant r$. 